\title{
TRANSFORMAÇÃO DA ARQUITETURA DE PROCESSOS DA CADEIA DE SUPRIMENTOS DE UM HOSPITAL QUATERNÁRIO DA CIDADE DE SÃO PAULO
}

\section{Autora: Alessandra Pereira \\ Co- autora: Lilian Calado Cavalcante Montano}

\section{Introdução}

Um dos desafios da área na Gestão em Saúde é exercer a assistência ao paciente com qualidade, eficiência e aplicação correta dos recursos, sem ultrapassar o orçamento previsto. 0 presente trabalho buscou descrever uma reconfiguração na arquitetura de processos da cadeia de suprimentos de um hospital quaternário da cidade de São Paulo que passou de uma estrutura que funcionava de forma compartimentada para um modelo em grupos responsáveis por todo o processo de aquisição.

\section{Método}

Trata-se de estudo quanti-qualitativo, feito por meio da coleta dos dados de produção de 2014, com implantação em 2015.

Até 2015 o Núcleo de Infraestrutura e Logística (NILO) era estruturado de forma descentralizada, por meio de equipes responsáveis divididas pelas fases dos processos de aquisição, sendo elas: abertura de processos, pesquisa/referência de preço, preparação do edital para licitação, licitação, compras (exceto o pregão) e empenho. Como essa estrutura apresentava dificuldades, pois os lead times eram altos, não tinham um planejamento adequado e existia uma dificuldade de informação em toda a cadeia de suprimentos o que consequentemente impactava no nível de serviço e a operação hospitalar, era necessário reestruturála para garantir o bom atendimento ao paciente.

Diante dessas dificuldades a diretoria avaliou a oportunidade de uma transformação de sua arquitetura, por meio de compras lean, com foco na melhoria e eficiência da cadeia de suprimentos. $O$ modelo proposto foi rearranjar as equipes em grupos, por tipos de materiais, com um responsável pelo processo desde a chegada da solicitação da demanda até o atendimento da mesma. Com essa mudança, o NILO ficou dividido em 5 grandes grupos: Medicamento, Material Médico-Hospitalar e OPME, Laboratório e EPI, Nutrição e diversos e Serviços.

\section{Resultado}

Na figura 1 é possível verificar o aumento de contratos dos itens classificados como curva A (itens com consumo que representam 84\% do valor de consumo no ano) que passou de 76\% em 2014 para $90 \%$ em 2017; curva B ( $14 \%$ do valor de consumo anual) e curva C ( $2 \%$ do valor de consumo). Como resultado, é possível observar também a melhora no melhor nível de serviço nos Institutos, que passou de $68,4 \%$ para $97,5 \%$ na farmácia do hospital e de $64,2 \%$ para $91 \%$ no almoxarifado responsável pelo atendimento de material médico hospitalar.

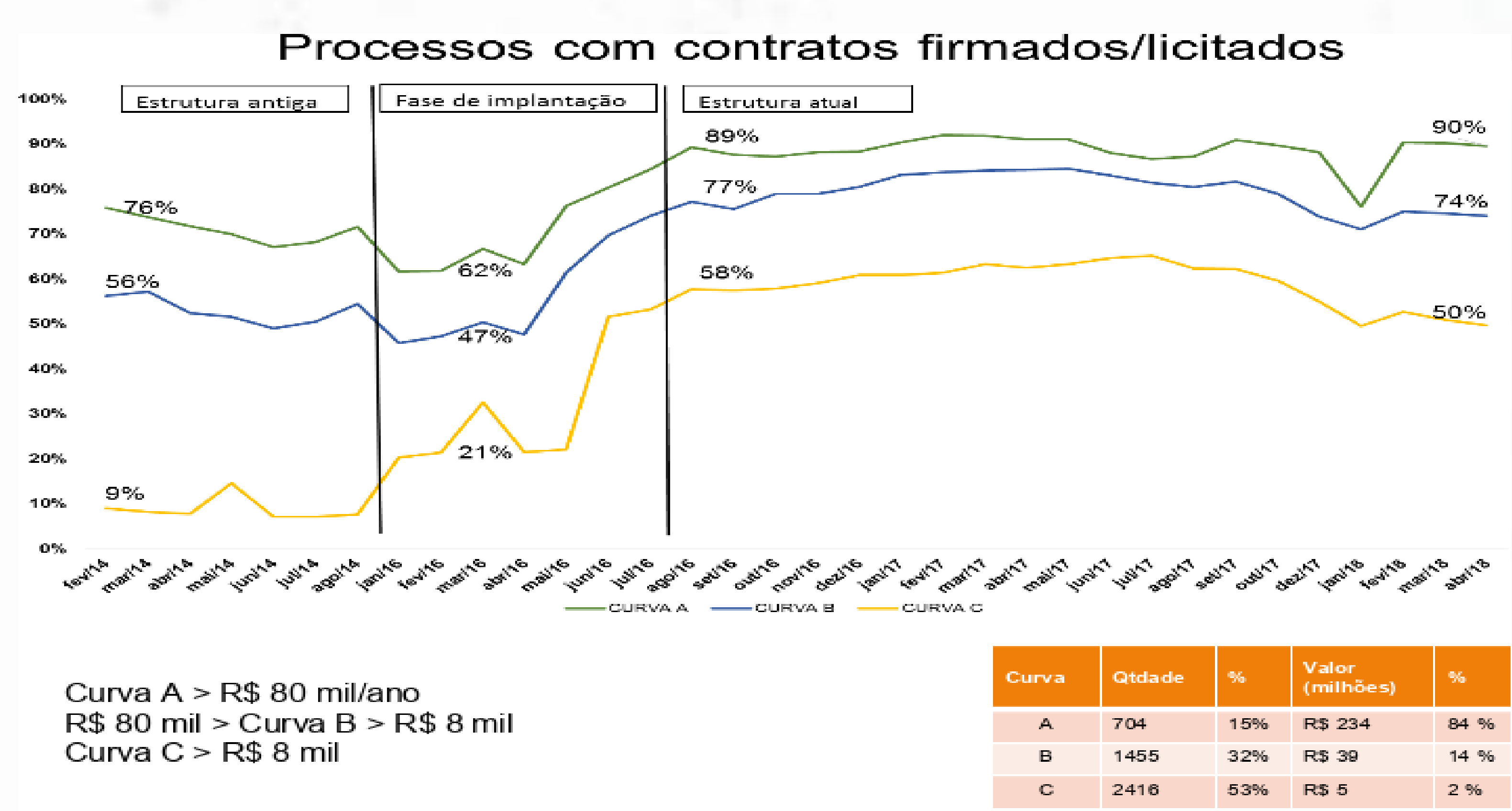

\section{Conclusão}

Foi verificado que em um trabalho de elaboração da Arquitetura de Processos da Cadeia de Suprimentos, é necessário considerar três pilares (Scarcelli, 2017):

Alinhamento estratégico: o desenho da Cadeia de Suprimentos precisa estar aderente à estratégia da organização;

Visão dos trade-offs e capacidade de coordenação: é preciso ter clareza das escolhas que são feitas e assegurar capacidade de execução destas escolhas dentro da organização;

Geração de valor: definir os valores a serem gerados na gestão da Cadeia de Suprimentos, ou seja, qual é a influência que a operação terá nos resultados da organização.

\section{Bibliografia}

AREDES, E. L. Método de Elaboração de Arquitetura de Processos para a Promoção de Gestão por Processos em Instituições de Ensino Superior Públicas, 2013.

DUMAS, M.; ROSA, M. LA; MENDLING, J.; REIJERS, H. A. Process Identification. Fundamentals of Business Process Management. p.3361, 2013. Berlin, Heidelberg: Springer Berlin Heidelberg.

Scarcelli, M (2017), Notas de apresentação, MPGC Supply Chain, em 20/10/2017. 